\title{
A IMPORTÂNCIA DA LITERATURA INFANTIL NA COLETA DE DADOS E NA ESTIMULAÇÃO DE FALA INICIAL
}

\author{
Maria de Fátima de Almeida Baia \\ Doutora em Linguística pela Universidade de São Paulo (USP) \\ Professora Adjunta da Universidade Estadual do Sudoeste da Bahia (UESB) \\ baiamfa.ling@gmail.com
}

\section{RESUMO}

Neste estudo, apresentamos um relato sobre uso de Literatura Infantil na coleta de dados de desenvolvimento linguístico de crianças com desenvolvimento típico. Após apresentar a literatura na área de Psicolinguística sobre desenvolvimento da linguagem e sobre a Literatura Infantil, discutimos os métodos de coleta de dados. Com intuito de mostrar a importância do uso desse tipo de literatura, apresentamos exemplos de sessões de coleta e estimulação de fala de crianças de 2-3 anos. Por fim, descrevemos os aspectos linguísticos que foram trabalhados por meio da leitura de diferentes obras.

Palavras-chave: desenvolvimento $\mathrm{da}$ linguagem, literatura infantil, coleta de dados.

\begin{abstract}
In this study, we present a discussion on the use of Children's Literature in language development data collection of children with typical development. After presenting the Psycholinguistics literature on language development as well as on Children's Literature, we discuss methods of collecting children's data. In order to show the importance of the use of this literature, we present examples of sessions of data collection and speech stimulation of children aged from 2 to 3 years old. Finally, we describe the linguistic aspects stimulated by the reading of different books.
\end{abstract}

Keywords: language development, children's literature, data collection. 


\section{Introdução}

Neste estudo, dissertamos a respeito da importância do uso da literatura infantil na estimulação de fala inicial e na coleta de dados de desenvolvimento linguístico com base na perspectiva da Complexidade (LARSEN-FREEMAN; CAMERON, 2008; MORIN, 2011).

No desenvolvimento da linguagem, há a emergência da linguagem fônica e estrutural, que não deixa de ser acompanhada por gestos manuais. Wallon (1941), por exemplo, aponta a importância dos gestos para o surgimento das primeiras palavras, os nomes propriamente ditos. Há até quem aponte a importância de se ensinar gestos para as crianças no início do desenvolvimento, como as pediatras Linda Acredolo e Susan Goodwyn (2003), que alegam que, no primeiro estágio de aquisição, as crianças ficariam frustradas por não poderem ainda pronunciar as palavras devidamente. Se ficam frustradas ou não, não se sabe, o que sabemos é que desde o início a criança arrisca com o que já está disponível na sua gramática inicial, criando até novos léxicos ou utilizando os existentes de forma bem simplificada.

Esse interesse pela linguagem infantil não é recente, por isso encontramos hoje uma infinidade de trabalhos com diferentes visões. Além das diferentes perspectivas, o campo do desenvolvimento linguístico é caracterizado por diferentes métodos de coletas de dados e investigação.

Os registros que temos de especialistas interessados no desenvolvimento da linguagem surgiram há pouco tempo. Ingram (1989) apresenta as principais e diferentes formas de registros que deram início aos estudos que hoje prosseguem: 
i.Estudos com diários (1876 - 1926) - os primeiros estudos sobre a aquisição da linguagem começaram a surgir há mais de cem anos atrás. Os diários eram feitos pelos pais, na maioria das vezes linguistas, que anotavam fatos a respeito do desenvolvimento linguístico dos filhos.

ii.Estudos com maiores amostras (1926 - 1957) - Esse tipo de estudo com maiores amostras se distancia do estudo longitudinal, pois são dados de crianças e faixas etárias diferentes. No entanto, é um bom meio para se estudar certos tipos de comportamento/produções em um determinado período e com um número maior de crianças.

iii.Estudos longitudinais (1957 até o presente) - Apesar dos estudos com diários se aproximarem dos estudos longitudinais, eles não são do mesmo tipo. Os estudos com diários eram anotações feitas sem um intervalo controlado de tempo, por exemplo. O estudo longitudinal consiste em transcrições de gravações realizadas durante um intervalo fixo de tempo.

Ao lado dos estudos que instruem a maneira pela qual os dados devem ser coletados, temos diferentes vertentes teóricas que tentam explicar o desenvolvimento linguístico da criança. Uma delas é a Empirista, que tem suas origens nas ideias de John Locke, filósofo iluminista britânico do século XVII, considerado o fundador do Empiricismo e da teoria geralmente chamada "tabula rasa" (ardósia em branco). Para o filósofo e seus seguidores, as crianças começariam sabendo absolutamente nada e aprenderiam por meio da experiência, da tentativa e do erro. A teoria que dá sequência ao que é defendido pelos seguidores de Locke é o Behaviorismo, resumida na obra de Skinner (1957), na qual é afirmado que comportamento linguístico e não linguístico são 
aprendidos por meio de estímulos, reforços e privações. Ademais, a teoria Behaviorista vai afirmar que o aprendizado linguístico pode ser comparado a qualquer outro aprendizado, ou seja, o conhecimento que um indivíduo tem da linguagem, por exemplo, seria obtido da mesma maneira que qualquer outro conhecimento.

Uma outra vertente, que tem suas origens no Racionalismo filosófico, é a Gerativa (CHOMSKY, 1975; 1981). O início do Racionalismo deu-se com as ideias do filósofo René Descartes no século XVII, as quais se manifestavam contra as dos empiristas. O racionalismo cartesiano, influenciado por algumas ideias de Platão, designa-se por inatista pelo fato de considerar que o indivíduo nasce com ideias inatas consideradas sementes de verdade. Seguindo os pressupostos cartesianos a respeito da origem das ideias, o Gerativismo incorpora o inatismo para explicar o surgimento da linguagem, consolidando-se, assim, como uma abordagem inatista na área Psicolinguística.

A abordagem psicogenética com os seus três grandes representantes (Piaget, Vygotsky e Wallon) não pode deixar de ser mencionada quando o assunto abrange desenvolvimento infantil. Cabe mencionar que nenhum desses autores psicogenéticos tem como questão principal o desenvolvimento da linguagem, porém eles não deixam de mencioná-la em seus estudos. Por exemplo, Piaget (1967), numa abordagem cognitivista, está preocupado com o desenvolvimento dos processos cognitivos e não direciona uma atenção especial para o desenvolvimento linguístico, pois para o pesquisador suíço o desenvolvimento da linguagem pode ser comparado ao desenvolvimento de outros processos cognitivos. Por essa razão, não podemos negar que temos a linguagem embutida nas suas preocupações gerais, embora o pesquisador priorize o desenvolvimento da inteligência e depois o do pensamento. Vygotsky, em uma perspectiva interacionista, pode ser considerado o mais linguista dos três autores. Na sua 
obra Pensamento e linguagem (1988), menciona os trabalhos de linguistas estruturalistas e o surgimento da análise fonológica, além de deixar explícito o seu enfoque principal: a relação entre pensamento e linguagem. A função primordial da linguagem para Vygotsky é a comunicação, o intercâmbio social; dessa maneira, o autor não deixa de reconhecer o domínio inconsciente da língua por parte da criança. Wallon, o último dos psicogenéticos a ser mencionado, focaliza a integração do organismo-meio, integração dos conjuntos funcionais - emoções, sentimentos e paixão - e o papel da afetividade nos diferentes estágios. Na sua obra A evolução psicológica da criança (1941), o autor afirma a existência de centros especializados para o surgimento da linguagem, mas nega a existência de uma linguagem pré-formada.

Além de todas essas vertentes teóricas sobre o desenvolvimento linguístico e cognitivo inicial, há a do paradigma da Complexidade, no qual este estudo se apoia. Tratase de um paradigma que vem dos estudos das Ciências Exatas e Naturais (THELEN; SMITH, 1994), defendendo a multidisciplinaridade nos estudos científicos (MORIN, 2011). Dessa maneira, uma abordagem com base na Complexidade abre o leque para um estudo interdisciplinar de diferentes áreas, como o diálogo entre a Psicolinguística, em específico a sua subárea de desenvolvimento da linguagem, e a Literatura Infantil.

No que se refere à perspectiva da Complexidade, ou dos Sistemas Adaptativos Complexos, uma das características fundamentais é a tentativa de explicar o que é o caótico, aquilo que aparentemente é desviante no percurso, por meio de uma perspectiva emergentista nos estudos de desenvolvimento cognitivo. É sabido que uma teoria de desenvolvimento precisa oferecer explicação acerca do surgimento do novo, das regularidades ao longo do trajeto e da precisão de determinados momentos de mudança que tendem a acontecer da mesma maneira em diferentes indivíduos. Dessa maneira, o 
que a perspectiva tende a enfatizar é que não se pode ignorar a diversidade, variedade, flexibilidade e assincronia que tendem a ocorrer no processo de desenvolvimento. Além disso, Morin (2011), a voz do pensamento filosófico da Complexidade, defende o caráter interdisciplinar da perspectiva e da ciência quando leva o paradigma em consideração.

\section{Estimulação da leitura e escrita de acordo com a Complexidade}

Morin (2011), na sua célebre obra Os sete saberes necessários à educação do futuro, explica o seu posicionamento não como um tratado sobre a relação de disciplinas que devem ser ensinadas, mas sim como uma exposição de problemas centrais ou fundamentais que permanecem esquecidos e ignorados no ensino em geral. Esses problemas são destacados e discutidos em cada saber que o filósofo apresenta como necessário para a educação:

i. As cegueiras do conhecimento: o erro e a ilusão - Morin (2011, p. 19) lembra que a educação deve reconhecer que não há conhecimento que não esteja, de certa maneira, ameaçado pelo erro e pela ilusão. Segundo o filósofo, é papel do cientista e do professor de destacar as interrogações na propagação do saber;

ii. Os princípios do conhecimento pertinente - o conhecimento pertinente para o autor é o conhecimento compartilhado, aquele que dialoga com outras áreas do saber: "Não se trata de abandonar o conhecimento das partes pelo conhecimento das totalidades, nem da análise pela síntese; é preciso conjuga-las" (p. 42);

iii. Ensinar a condição humana - por uma educação universal centrada na condição humana, a qual deve ser entendida como parte de um universo e não a separar dele. Somos uma amálgama de condições, carregamos a condição cósmica, a condição 
física e também a condição terrestre, segundo Morin. O autor complementa esta nossa natureza complexa afirmando que "Somos seres infantis, neuróticos, delirantes e também racionais $[\ldots]^{\prime \prime}$ (p. 53);

iv. Ensinar a identidade terrena - neste saber, nosso papel como educador é inscrever em nós e nos nossos aprendizes a consciência antropológica, a consciência ecológica, a consciência cívica terrena e a nossa própria consciência espiritual, no sentido do exercício complexo do pensamento;

v. Enfrentar as incertezas - relacionado com o primeiro saber, este saber destaca a nossa total falta de controle sobre os acontecimentos. Segundo o autor, "[...] o conhecimento é a navegação em um oceano de incertezas, entre arquipélagos e certezas" (p. 75);

vi. Ensinar a compreensão - neste saber, Morin destaca a importância de argumentar e refutar no lugar de excomungar; a importância da tolerância e da escuta atenciosa mesmo que os ideais do outro sejam diferentes do nosso;

vii. A ética do gênero humano - além da tolerância, Morin afirma que devemos proteger a diversidade dos ideais, o que caracteriza uma democracia. O filósofo destaca a necessidade de conservar a pluralidade para conservarmos a nós mesmos (p. 96).

De acordo com a perspectiva da Complexidade, é necessário que em um ambiente de ensino cada um desses saberes seja levado em consideração. No presente estudo e nas sessões apresentadas, destacamos o saber iii, isto é, ensinar a condição humana. Segundo o próprio autor, na obra A cabeça bem-feita (2015, p. 43),

[...] o estudo da linguagem, sob a forma mais consumada, que é a forma literária e poética, ele nos leva diretamente ao caráter mais original da condição humana, pois, como disse Yves Bonnefoy, "são as palavras, 
com seu poder de antecipação, que nos distinguem da condição animal". E Bonnefoy enfatiza que a importância da linguagem está em seus poderes e não em suas leis fundamentais.

Ademais, os três princípios de incerteza do conhecimento, levantados por Morin na mesma obra, têm relação com o próprio exercício da linguagem: i) princípio cerebral o conhecimento nunca é uma cópia direta do real, mas sempre uma tradução ou construção; ii) princípio físico - o conhecimento de qualquer fato está sempre dependente da interpretação dada a ele; iii) princípio epistemológico - segundo o autor, surge da crise dos fundamentos da certeza, sendo iniciado por Nietzsche na filosofia e na ciência, em geral, a partir de Popper e Bachelard (MORIN, p. 59).

No que se refere diretamente ao texto e ao seu ensino, Laidlaw (2005), na sua obra sobre letramento e Complexidade, destaca a importância de entendermos a sala de aula e a própria escola como um sistema complexo por ser difícil explicar o seu funcionamento usando método redutivo da ciência tradicional. O grupo de alunos, segundo a autora, é um sistema complexo composto por organismos complexos, e a perspectiva da Complexidade permite que o foco esteja nos padrões de comportamento e nas relações dinâmicas que emergem. A partir do momento que começa haver interação entre os alunos e entre aluno e professor, novos padrões surgem e começam a ser observados. Acontece, então, uma auto-organização por meio da adaptação que aos poucos acontece.

No que se refere ao texto, ao nível linguístico que ultrapassa o da frase, a perspectiva da Complexidade, segundo Larsen-Freeman e Cameron (2008), entende a sua construção como uma atividade linguística dinâmica e complexa. Assim como nos outros 
níveis linguísticos, encontramos na construção do texto padrões de estabilidade e de variabilidade, fundamentais à emergência de qualquer sistema complexo.

Segundo as autoras, quando movemos do discurso oral para o escrito, passamos de uma realidade instantânea e intangível para uma realidade demorada e concreta. 0 texto em si não é dinâmico, ele é fixo e imutável. Contudo, ele pode fazer parte de múltiplos sistemas complexos durante a sua composição, a sua leitura e o seu uso. $\mathrm{Na}$ leitura, por exemplo, afirmam Larsen-Freeman e Cameron (2008), temos a influência de valores culturais e expectativas contextuais.

Ademais, lembram as autoras, conforme o texto é composto, ele passa por diferentes versões, as quais são caracterizadas por adaptações. Toda essa dinâmica não opera apenas no nível do texto, mas na relação do texto com demais níveis linguísticos. Eventualmente, o texto se estabiliza se tornando um atrator de ponto fixo na sua trajetória composicional (LARSEN-FREEMAN; CAMERON, 2008, p. 187).

Em relação aos gêneros textuais, as autoras, com base em Bakthin (1986), vão entender que um gênero organiza a maneira como conceitualizamos e entendemos o mundo; os gêneros são formas estabilizadas de expressar o mundo (LARSEN-FREEMAN; CAMERON, 2008, p. 189). Entretanto, apesar de entenderem o gênero como uma forma estabilizada de expressão, as autoras lembram que qualquer simplificação da noção de gênero perde algo de sua complexidade. Dessa maneira, apesar de ser um padrão estabilizado, o gênero não está fechado/imutável.

Por fim, são poucos os estudos sobre texto em língua materna e a sua composição na literatura da Complexidade. Todavia, conforme Larsen-Freeman e Cameron (2008, p. 193) defendem, podemos concluir, com base nos trabalhos citados, que uma perspectiva da Complexidade para o trabalho com o texto requer que conectemos descobertas e 
teorias empíricas da Psicologia Cognitiva, da Sociolinguística, da Análise da Conversação, da Psicolinguística, da Linguística textual e da Pragmática. Neste estudo, adicionamos mais uma área de descobertas, a da Literatura Infantil.

\section{A literatura infantil e sua importância no trabalho com a primeira infância}

Hunt (2010), em sua obra Crítica, teoria e literatura infantil, situa a Literatura Infantil em um cenário interdisciplinar por requerer contribuição de outras disciplinas ao atravessar fronteiras acadêmicas, históricas e linguísticas. Dessa maneira, já teria em si uma natureza complexa, de acordo com os parâmetros da perspectiva da Complexidade (MORIN, 2011).

Entendemos, neste estudo, a Literatura Infantil como um instrumento causador de mudanças, logo, um mecanismo que pode ativar a auto-organização por ser entendida como um atrator ou estado atrator. Os sistemas dinâmicos e complexos apresentam, em geral, três tipos de atratores: ponto fixo, periódico e caótico. Considerando a linguagem e a cognição como sistemas complexos, podemos entender que: a) o ponto fixo seria o conhecimento já adquirido associado ao novo conhecimento; b) o atrator periódico seria a própria cognição; e os outros atratores caóticos, ou atratores estranhos seriam os diversos fatores que interferem na aprendizagem (interação, input, materiais, etc.) (PAIVA, 2005). Sendo assim, entendemos que o uso da Literatura Infantil na coleta de dados de desenvolvimento da linguagem desempenhe o papel de atrator caótico ou estranho. 
A respeito dos benefícios do uso da Literatura Infantil no contexto de desenvolvimento da linguagem, com base em Hunt (2010), destacamos a dupla contribuição desse tipo de atrator: a) contribuição histórica - por ser uma contribuição valiosa à história social, literária e bibliográfica, nas quais a criança se encontra imersa a partir do momento em que há contato com o livro; b) contribuição contemporânea - seu papel na alfabetização e na cultura ao apresentar a relação entre o oral e o escrito, isto é, a relação entre imagem e palavra. Ademais, segundo o mesmo autor, destacamos também o panorama de gêneros que caracteriza o universo da Literatura Infantil: narrativa para escola, textos dirigidos a cada um dos sexos, fantasia, conto popular, contos de fada, entre outros. No que se refere aos contos,

\begin{abstract}
A literatura para crianças hoje abrange diferentes tipos de contos, entre os tradicionais e os modernos. Segundo Léon, os contos tradicionais (contos de fada, contos maravilhosos etc.) "tocam aspectos muito importantes de nossa natureza e de nossa história [pois] o conto constrói/estabelece o ser humano como um ser de linguagem e de cultura [...] Ao lado deles, temos os contos modernos: para Léon, "são narrativas originais, criadas por autores contemporâneos, que não têm nada a ver com tradição oral [popular], mas que trazem uma certa renovação do maravilhoso [...] abordam o dia a dia das crianças [...] (FARIA, 2012, p. 24).
\end{abstract}

No que se refere ao material com o qual a criança em período inicial de desenvolvimento da linguagem entra em contato, destacamos que lidar com primeira infância é mergulhar em um contexto no qual a ausência de abstração é compensada pela presença da concretude, como Palo e Oliveira (1992) afirmam. Além disso, sabemos que a criança não é um "adulto em miniatura", pois sua cognição opera por associações simples de pensamento e sua linguagem apresenta uma gramática própria em emergência (BAIA, 2013). 
Dessa maneira, é levando em consideração a estrutura simples linguística infantil que buscamos, ao lidar com bebês e crianças, um tecido melódico composto por aliterações, assonâncias, rimas, ritmo sincrônico, isto é, metros regulares e breves, que, segundo Bordini (1991), não são apenas um retrato da linguagem infantil emergente; eles têm sido utilizados para aquietar a criança e/ou expressar-lhe afeto. Assim, o profissional que lida com primeira infância na tarefa educativa, de estimulação de fala, entre outras, deve ter conhecimento dessas estratégias que funcionam como uma espécie de meio para que ocorra a vinculação com a criança.

Quando tratamos de Literatura Infantil, incluímos tanto o seu formato em poesia quanto o seu formato em prosa. Sabemos que crianças aprendem e muito por meio de histórias, pois por meio delas trabalhamos diversos fatores, tais como: habilidade narrativa (descrição de eventos e objetos), ordem de eventos (início, meio e fim), manuseio de livros e meios digitais e novo léxico. Outrossim, no trabalho com literatura infantil, envolvemos diferentes práticas como: leitura, conversa, canto, escrita, desenho, jogos, etc. Tudo isso é possível porque a razão teleológica da Literatura Infantil, desde os seus primórdios, segundo Lucas (1987), é educar e divertir. Nos estudos com linguagem, adicionamos mais uma função, a sua capacidade de auxiliar no exercício de estimulação de linguagem, como relatamos a seguir.

\section{Método de coleta e transcrição}

Os estudos sobre desenvolvimento da linguagem dividem-se em estudos de percepção, compreensão ou produção. O primeiro investiga se indivíduos, de feto a 
adultos, percebem os sons da língua; o segundo investiga o que a criança compreende; e o terceiro investiga o surgimento dos sons e os processos linguísticos.

Em geral, os estudos sobre o desenvolvimento linguístico são de caráter observacional (naturalístico) ou experimental. Como apresentamos anteriormente, o observacional foi o primeiro método de coleta de dados de fala das crianças, realizado por meio da escrita de diários mantidos por psicólogos e linguistas que acompanhavam, na maioria das vezes, o desenvolvimento de seus filhos. Quando usado o método observacional, não é designado um estímulo específico para o participante, pois produção, percepção e compreensão da linguagem ocorrem em uma situação normal (naturalística e espontânea) de interação entre o falante e o ouvinte. No segundo tipo de método de coleta de dados, o experimental, um conjunto de estímulos é elaborado de maneira controlada, i.e., pré-estipulada. Os dados são recolhidos seguindo alguma técnica de elicitação em laboratórios ou em outro ambiente adequado à condução do experimento. Os dois tipos de métodos compartilham etapas de elaboração, embora difiram em duas delas:

Quadro 1: Comparação entre métodos de estudo (BAIA, 2008)

\begin{tabular}{|c|c|c|}
\hline Passos para geração dos dados & Experimental & Observacional \\
\hline 1. Formular a hipótese & Sim & Sim \\
\hline 2. Desenvolver o design & Sim & Não \\
\hline 3. Construir método de elicitação & $\operatorname{Sim}$ & Não \\
\hline 4. Selecionar população & Sim & Sim \\
\hline 5. Coletar dados & Sim & Sim \\
\hline
\end{tabular}


O presente estudo apresenta sessões observacionais. A escolha metodológica e os dados analisados são explicados a seguir.

\subsection{A escolha metodológica}

Por ser um estudo que abrange dados iniciais e de transição do balbucio às primeiras palavras, o método mais adequado é o observacional. O uso de fala espontânea da criança, além de refletir melhor o desenvolvimento linguístico, permite a coleta de dados desde balbucio até palavras. O uso do método observacional é também crucial para a coleta de diferentes tipos de produções que tendem a ocorrer simultaneamente, ou seja, balbucio sendo produzido concomitantemente às palavras de diferentes classes gramaticais.

Em geral, os estudos linguísticos partem dessa definição e se baseiam em algum método específico de transcrição, como, por exemplo, o CHAT (CHILDES). Esse sistema de transcrição de dados utilizado está na plataforma Child Language Data Exchange System (CHILDES). De acordo com MacWhiney (2000), o autor do sistema de transcrição, com ele é possível facilitar a análise de dados devido à sua automatização, adquirir dados mais consistentes e disponibilizar mais dados para um número maior de crianças não só com idades diferentes, mas também falando diversas línguas.

Dessa maneira, todas as transcrições pertencentes ao banco de dados são colocadas no sistema de transcrição CHAT (Codes for the Human Analysis of Transcripts), o que faz com que variadas pesquisas de diferentes análises possam utilizar desse sistema. Além de ser gratuito, diversos grupos de pesquisa utilizam os programas CHILDES 
e inserem novos conjuntos de dados, que ficam disponibilizados para todos que fazem uso do banco de dados (MACWHINEY, 2000).

Assim, o linguista responsável pela coleta de dados tem pouco recurso lúdico para se basear na tarefa de estimulação de fala. Em geral, são utilizados meios explorados pelos estudos de pedagogia da primeira infância e/ou tarefas específicas de estimulação da fala.

\subsection{GEDEF (Grupo de Estudos de Desenvolvimento Fonológico)}

Apresentamos relatos de sessões de estimulação e coleta de dados que ocorreram nos anos de 2014 a 2017 na Universidade Estadual do Sudoeste da Bahia (UESB). Os dados coletados fazem parte do Banco de Dados do GEDEF (Grupo de Estudos de Desenvolvimento Fonológico), coordenado pela autora deste estudo, resultantes do projeto Padrões emergentes no desenvolvimento fonológico típico e atípico, com coleta aprovada pelo comitê de ética responsável na instituição (CAAE 30366814.1.0000.0055). Participaram dessa coleta, crianças de 8 meses a 5 anos, gêmeos e não gêmeos de ambos os sexos e com desenvolvimento típico. Cada sessão teve duração de 30 a 40 minutos.

No projeto de estimulação de fala, são coletados, mensalmente, dados de crianças com desenvolvimento típico para o banco de dados em andamento. As crianças participantes e seus respectivos cuidadores colaboram, voluntariamente, fornecendo dados que são analisados para levantamento de parâmetros de desenvolvimento típico. Na mesma instituição, contamos com núcleo de estudos de desenvolvimento de fala de crianças com síndrome de Down (Núcleo Saber Down), como também um espaço de recuperação de fala para afásicos (LAPEN - Laboratório de Pesquisa em Estudos de 
Neurolinguística), locais nos quais a autora deste trabalho atua como psicolinguista e musicoterapeuta.

\section{Relato das sessões}

As sessões relatadas são de duas crianças, uma do sexo feminino (I) e outra do sexo masculino (D), nativas de Vitória da Conquista - BA, com desenvolvimento típico. 0 período etário explorado é de 2-3 anos.

Quadro 2: Crianças participantes da coleta de dados

\begin{tabular}{|l|l|l|}
\hline Crianças participantes & Faixa Etária & $\begin{array}{l}\text { Descrição geral do } \\
\text { contato com a } \\
\text { expressão musical } \\
\text { e corporal }\end{array}$ \\
\hline D. & $2-3$ anos & $\begin{array}{l}\text { Menino com } \\
\text { desenvolvimento } \\
\text { típico. Muito } \\
\text { extrovertido. } \\
\text { Participou das } \\
\text { coletas de dados } \\
\text { no GEDEF do seu } \\
\text { primeiro ano ao } \\
\text { terceiro de vida. } \\
\text { Sua preferência nas } \\
\text { sessões foram: } \\
\text { brinquedos, } \\
\text { instrumentos livros } \\
\text { musicais e } \\
\text { infantis. }\end{array}$ \\
\hline
\end{tabular}




\begin{tabular}{|l|l|l|}
\hline I. & $2-3$ anos & $\begin{array}{l}\text { Menina com } \\
\text { desenvolvimento } \\
\text { típicor Muito } \\
\text { comunicativa. Foi } \\
\text { acompanhada no } \\
\text { GEDEF dos 2 aos 5 } \\
\text { anos de idade. Sua } \\
\text { preferência nas } \\
\text { sessões sempre } \\
\text { foram os livros } \\
\text { infantis. }\end{array}$ \\
\hline
\end{tabular}

\subsection{Coleta de dados com D}

A seguir, relatamos duas sessões de coleta de dados e estimulação de fala de D. com uso de literatura infantil.

1. Sessão 1 com D - estimulação de fala com uso do livro Cena de rua de Ângela Lago (2000).

Figura 1: D. na sessão com 2 anos (GEDEF)

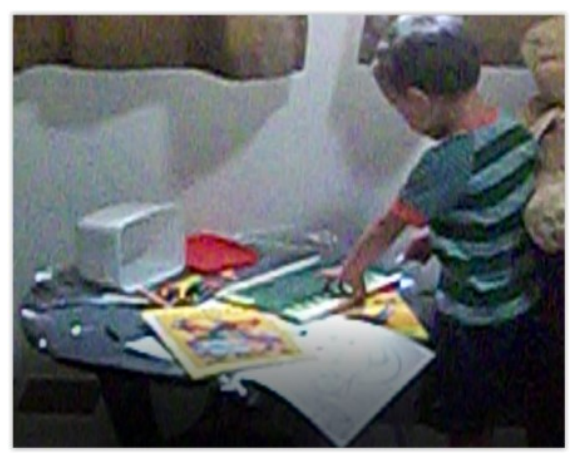

Essa obra de Lago contém apenas ilustrações. Por haver ausência de escrita, a criança e o contador de histórias ficaram mais livres para improvisar. Trata-se da história 
de um menino que vende mercadorias no farol e não é bem tratado pelas pessoas que passam por ele. Ao longo da sessão com a leitura do livro, D. utiliza o vocabulário conhecido, palavras como carro, menino, cão, fruta, como também trabalha na expansão de outras palavras tais como trânsito e motorista. Ademais, por ser uma história que foca acontecimentos no trânsito, a pesquisadora contadora pôde trabalhar estimulação de sons bilabilais com onomatopeias como bibibi para buzina de carro, além de utilizar os mesmos segmentos para trabalhar o terceiro saber proposto por Morin, a saber, ensinar a condição humana. Na ocasião, como trecho da transcrição apresenta, D. explica o que devemos falar ao recebermos um presente por mais simples que seja:

(1) *CHI: obrigado $\mathrm{p}(\mathrm{r})$ esente.

\%pho: bi.'ga.dv be.'zẽ.tji

2. Sessão $\mathbf{2}$ com $\mathbf{D}$ - estimulação de fala com uso do livro $O$ que tem dentro da sua fralda? de Guido van Genechten (2014).

Figura 2: D. na sessão com 3 anos (GEDEF)

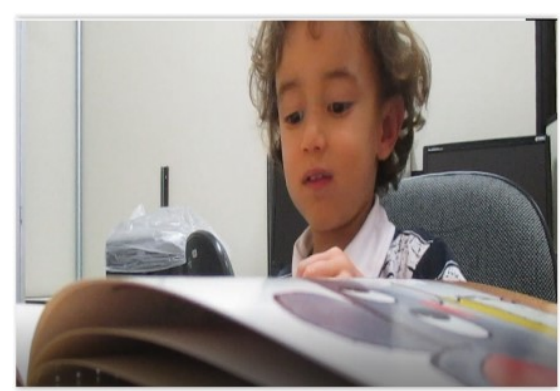

A obra de Van Genechten, um ilustrador e autor de Flandres, traduzida por Vânima Maria A. de Lange, é uma das favoritas pelas crianças do GEDEF. Nela, um ratinho 
curioso sai olhando o que dentro das fraldas de outros animais. O livro permite que a criança abra a fralda junto com os personagens para saber se está limpa ou suja. Nesta sessão, D. trabalhou a expansão de vocabulário com nome de animais e dos seus filhotes, nomes com diminutivos ou outra formação lexical, por exemplo, coelho, cabrita, cachorrinho, bezerro, ratinho, porquinho, potrinho e afins. Na idade de três anos, o trabalho de estimulação de fala não está mais com foco em aspectos fônicos, como acontece até os dois anos; ele passa a focar construções morfológicas de palavras e expansão lexical. No exemplo retirado da transcrição da sessão, D. apresenta a distinção morfológica do feminino de leão como também sua forma plural:

(2) ${ }^{*} \mathrm{CHI}$ : uma leoa foi para a casa $\mathrm{xxx}$ todos leões de [//] é de $\mathrm{xxx}$. ii \%pho: 'u.me 'le.o.a for pa 'ka.ze \$ 'to. $\overline{d z} I$ le. 'õI $\widehat{d z} I \varepsilon \widehat{d z} I \$$

\subsection{Coleta de dados com I.}

3. Sessão 1 com I - estimulação de fala com uso do livro Quem tem medo de quê? de Ruth Rocha (2010).

Figura 3: I. na sessão com 2 anos (GEDEF)

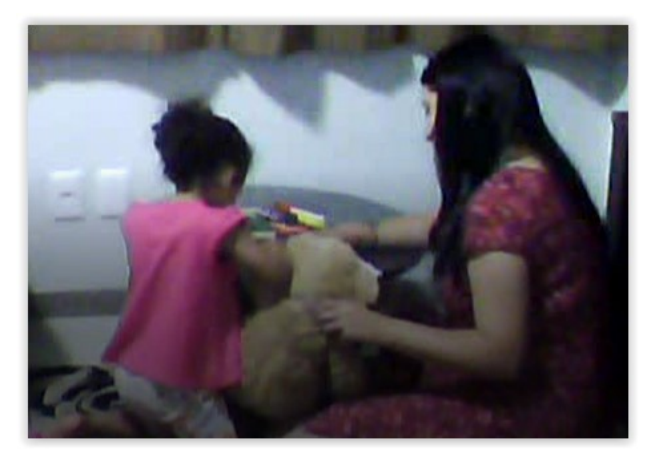


Durante todas as sessões, I buscou sempre a mesma obra, a sua favorita da Ruth Rocha. No início, pedia que a pesquisadora contasse a história, depois fazia o exercício de recontar. A obra de Ruth Rocha fala de medos que assolam a personagem principal dentro da sua própria casa, um mundo fantasioso com morcegos e bruxas. Nesta sessão em específico, trabalhamos entoação com l., diferindo a entoação de frases declarativas das interrogativas, o que é favorecido pelo texto da obra por apresentar diálogos entre as personagens com os dois tipos de entoação. Na figura 3, I. coloca o Leopoldo, um urso de pelúcia, no meio para contar toda a história para ele, enfatizando a entoação de pergunta. A seguir, exemplos de I. usando a entoação de declarativa afirmativa (3) e declarativa negativa (4):

(3) ${ }^{*} \mathrm{CHI}:$ eu go(s)tei desse.

\%pho: ev go.'ter 'de.sI

(4) ${ }^{*} \mathrm{CHI}$ : eu não sei.

\%pho: ev nũ seI

Na mesma sessão, com a presença da mãe (MOT), I. mantém uma conversa usando entoação de interrogativa:

(5) *MOT: depois a gente pinta, n(ão) é?

${ }^{*} \mathrm{CHI}: \quad(e m) b o(r a)$ pinta(r)?

\%pho: bo pĩ.'ta: 
Por fim, a obra utilizada na sessão, ao fazer I. passar por diferentes medos e situações com a personagem principal, tornou possível trabalharmos o saber a condição humana, ao mostrarmos o social entrelaçado com o individual no momento em que houve projeção da vivência de I. na da personagem.

4. Sessão $\mathbf{2}$ com I - estimulação de fala com uso do livro O fantástico cachecol do vovô urso de Gillian Heal (2010).

Figura 4: I. na sessão com 3 anos (GEDEF)

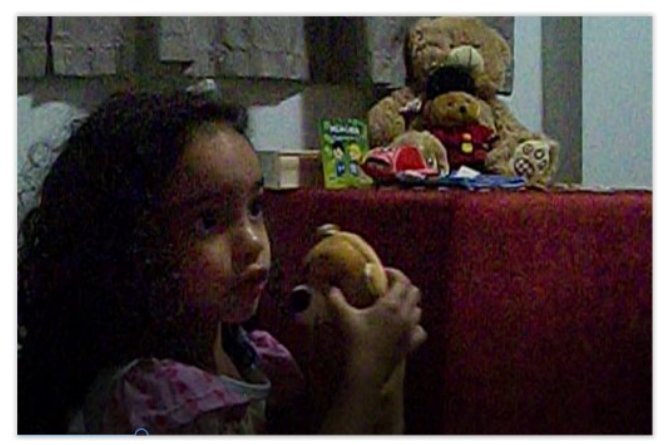

Nesta sessão, I. reconta a história da obra de Gilian Heal, traduzida por Aurea Arata, usando um fantoche de urso. Assim como na obra em que o vovô urso conta para seu neto os diferentes fios no seu cachecol, alguns para cima e outros para baixo, I. reconta mostrando as duas diferentes direções. Na sessão, o aspecto fônico trabalhado com ênfase foi a pronúncia de sílabas com ataque ramificado como em tricor, trabalho. Além de trabalhar a produção dos dígrafos, o repertório lexical de I. com relação às cores e medidas foi expandido, como a cor do urso:

(6) ${ }^{*} \mathrm{CHI}$ : marronzinha. 
\%pho: ma.xõ.'zĩ

Indubitavelmente, cada sessão, mesmo quando apenas um livro foi trabalhado, trouxe benefícios para a estimulação da linguagem. Dessa maneira, como exposto anteriormente, trabalhamos com dois tipos de atratores, segundo a visão da Complexidade (PAIVA, 2005), o gênero Literatura Infantil como atrator fixo, assim como Larsen-Freeman e Cameron (2008) o definem, e as obras utilizadas como atrator caótico, isto é, como meio de interferência na aprendizagem. A união desses dois atratores, na tarefa de estimulação de fala, foi, além de prazerosa, muito positiva.

\section{Considerações finais}

Apresentamos, neste estudo, alguns exemplos de sessões que evidenciam a importância do uso de literatura infantil no contexto de coleta de dados e estimulação de fala. Como apresentamos, mesmo que em poucos exemplos de sessões, o seu uso promove não só a estimulação linguística, foco da coleta, como também a estimulação da criatividade e expressão corporal da criança.

Todo cenário não apenas fortalece a importância da Literatura Infantil para os estudos da linguagem como também reforça a importância da interdisciplinaridade no trabalho com a primeira infância, assim como a perspectiva da Complexidade vem enfatizar (MORIN, 2011; 2015).

\section{Referências}


ACREDOLO, L.; GOODWYN, S. Sinais: a linguagem do bebê. São Paulo: M. Books, 2003.

BAIA, M. F. A. O modelo prosódico inicial do português brasileiro: uma questão metodológica? 2008. Dissertação (Mestrado em Linguística) Universidade de São Paulo, 2008.

. Os templates no desenvolvimento fonológico: o caso do português brasileiro. 2013.Tese (Doutorado em Linguística) Universidade de São Paulo, 2013.

BAKTHIN, M. Speech genres and other late essays. Austin: University of Texas Press, 1986.

BORDINI, M. G. Poesia infantil. São Paulo: Ática, 1991.

CHOMSKY, N. Reflections on language. Nova lorque: Pantheon Books, 1975. Lectures on government and binding: The Pisa lectures. Cambridge: MIT Press, 1981.

DESCARTES, R. Discurso do método. In: Os Pensadores. Rio de Janeiro: Nova Cultural, 1996.

FARIA, M. A. Como usar a literatura infantil na sala de aula. São Paulo: Contexto, 2012.

HEAL, G. O fantástico cachecol do vovô urso. Tradução Arata, A. São Paulo: Centro de Estudos Vida \& Consciência Editora, 2000.

HUNT, P. Crítica, teoria e literatura infantil. Tradução Cid Knipel. São Paulo: Cosac \& Naify, 2010.

INGRAM, D. First language acquisition: method, description and explanation. Cambrigde University Press, 1989.

LAGO, A. Cena de rua. Rio de Janeiro: RHJ, 2000.

LAIDLAW, L. Reinventing curriculum: a complex perspective on literacy and writing. Nova Jersey: Lawrence Erlbaum Associates, 2005.

Larsen-Freeman, D.; Cameron, L. Complex systems and applied linguistics. Oxford: Oxford University Press, 2008.

LOCKE, J. Os Pensadores. São Paulo: Nova Cultural, 1991.

LUCAS, F. Prefácio. In: ZILBERMAN, R.; MAGALHÃES, L. C. (orgs.). Literatura infantil: autoritarismo e emancipação. São Paulo: Ática, 1987. 
MacWHINNEY, B. The CHILDES Project: Transcription on Format and Programs. 3. ed. New Jersey: Lawrence Erlbaum, v. I e II, 2000.

MORIN, E. Os sete saberes necessários à educação do futuro. São Paulo, Cortez, 2011.

A cabeça bem-feita: repensar a reforma, reformar o pensamento. Tradução Eloá Jacobina. Rio de Janeiro: Bertrand Brasil, 2015.

PAIVA, V. L. M. O. Modelo fractal de aquisição de línguas. In: BRUNO, F. C. (org.). Ensinoaprendizagem de línguas estrangeiras: reflexão e prática em ensino/aprendizagem de língua estrangeira. São Paulo: Claraluz, 2005. p. 23-36.

PALO, M. J.; OLIVEIRA, M. R. D. Literatura infantil: voz da criança. São Paulo: Ática, 1992.

PIAGET, J. Seis estudos de Psicologia. Rio de Janeiro: Forense-Universitária, 1967.

ROCHA, R. Quem tem medo de quê? São Paulo: Global, 2010.

SKINNER, B. F. Verbal Behavior. Nova Iorque: Applenton-Century-Crofts, 1957.

THELEN, E.; SMITH, L. B. A dynamic systems approach to the development of cognition and action. Cambridge, MA: MIT Press, 1994.

VAN GENECHTEN, G. O que tem dentro da sua fralda? Tradução V. M. Lange. São Paulo: Brinque-Book Editora de Livros, 2014.

VYGOTSKY, L. Pensamento e linguagem. São Paulo: Martins Fontes, 1988.

WALLON, H. A evolução psicológica da criança. Lisboa: Edições 70, 1941.

Recebido em 25 de fevereiro de 2019.

Aceite em 4 de abril de 2019.

\footnotetext{
' Notação no formato CHAT de transcrição. CHI - Child (criança)/ \%pho: transcrição fonética do enunciado.

ii xxx: marcação de enunciado ininteligível na transcrição ortográfica/ \$: marcação de enunciado ininteligível na transcrição fonética.
} 